\title{
Feminismos em movimento no ciberespaço*
}

\author{
Fabiana Martinez**
}

\section{Resumo}

O objetivo geral deste artigo é compreender, através da descrição $e$ análise de algumas manifestações significativas da internet, o papel do ambiente web como locus de ação e reflexão na construção de uma nova epistemologia do conhecimento feminista, mais reticulada, fluida e multivariada. Em primeiro lugar, será discutida a relação histórica entre mulheres e redes sociais e o conjunto de discursos e manifestações feministas que eclodiram em 2015. Em seguida, traçamos um panorama do feminismo na internet, tratando da articulação entre grupos de discussão feministas do Facebook e blogs feministas. Dentro disso, é feita uma análise desses grupos, atentando para um fenômeno que vem chamando a atenção e que parece ser constitutivo do conhecimento feminista que ora se dissemina no espaço web: a segmentação bem marcada nesses espaços em "vertentes" (liberal, interseccional, marxista, queer ou LGBT e radical), que competem entre si, sobretudo no que tange à busca de entendimento por uma ontologia de gênero.

Palavras-chave: Feminismo, Internet, Redes Sociais, Conhecimento.

* Recebido em 08 de maio de 2017, aceito em 04 de dezembro de 2018.

** Professora de Antropologia do Departamento de História e Ciências Sociais da Universidade Federal de Goiás (UFG), Catalão, GO, Brasil. Pesquisadora do Dialogus - Estudos Interdisciplinares em Gênero, Cultura e Trabalho da UFG. fabiana_jordao@yahoo.com.br / é https://orcid.org/0000-0003-4675-0088. 
Feminisms in Movement in Cyberspace

\begin{abstract}
The general objective of this article is to understand, through description and analysis of some significant manifestations of the internet, the role of the web environment as a locus of action and reflection in the construction of a new epistemology of feminist knowledge that is more reticulated, fluid and multivariate. The article first discusses the historic relationship between women and social networks and the feminist discourses and manifestations that emerged in 2015. It then sketches an overview of feminism on the internet, examining the articulation between feminist discussion groups on Facebook and feminist blogs. An analysis of these groups is made, focusing on a phenomenon that has attracted attention and that seems to be constitutive of the feminist knowledge disseminated on the web: the well-marked segmentation of these spaces into "tendencies" (liberal, intersectional, Marxist, queer or LGBT and radical), which compete with each other, particularly in the search for understanding by a gender ontology.
\end{abstract}

Keywords: Feminism, Internet, Social Networks, Knowledge. 


\section{Introdução}

A teoria feminista ocidental possui uma narrativa hegemônica constantemente reproduzida em artigos científicos, aulas e cursos. Essa história é narrada através da noção de progresso, partindo de uma preocupação com igualdade $e$ semelhança nos anos 70, passando por diferença e diversidade nos anos 80 e indo em direção à fragmentação dos anos 90 (Hemmings, 2009). Nessa tecnologia da construção narrativa, o presente, ápice de um "conhecimento iluminado", é legitimado por um passado em que a escrita feminista da década de 70 aparece como "essencialista" e excludente e em contraposição a uma década de 80 sobrecarregada pelo conceito de gênero $e$ atenta para recortes de raça e classe, sobretudo, pelo epifenômeno do feminismo negro. Finalmente, os anos 90 são apresentados como o período em que as teorias pós-estruturalistas amealham as preocupações da década anterior, rompendo com o sujeito feminino no centro do debate e preocupando-se com "a subjetividade histórica de indivíduos sexuais e a corporeidade da identidade sexual, vista como indeterminada, ambígua, múltipla" (Morris, 1999, apud Hemings, 2009).

Contudo, fora da academia, é possível perceber que essa linearidade progressista tem sido perturbada pelos "feminismos" que emergem na internet. Como a maioria dos movimentos sociais, o feminismo tem se valido de uma dinâmica reticular formada pelas plataformas de comunicação digital - blogs, redes sociais, vídeos, para difundir e promover suas pautas $e$ reivindicações. Dentro dessa dinâmica, observa-se que nos últimos doze anos houve uma transformação em relação aos sujeitos desse debate, indicando a adesão cada vez mais precoce de jovens interessadas nas pautas feministas, o que está ligado diretamente ao fácil acesso e à familiarização desse público com as tecnologias ${ }^{1} \mathrm{O}$ crescente interesse pela temática feminista revela

1 Em pesquisa exploratória sobre produções acadêmicas relacionadas ao tema, constatou-se que os "jovens" aparecem entre os sujeitos mais pesquisados quando o assunto é "rede social digital", representando um percentual de 53,6\% 
tanto o aumento dos espaços ocupados pelas feministas na internet quanto o extravasamento de suas preocupações para espaços da mídia internacional. ${ }^{2}$ Através da atualização contínua dos seus significados, essa nova "consciência feminista" tem sugerido uma nova política teleológica que congrega novas estratégias e formas de (re)produção do conhecimento.

$\mathrm{Na}$ verdade, o alargamento e a capilaridade do campo discursivo do feminismo indicam que sua compreensão já não pode ser demandada a partir de antigas categorias ou modelos de articulação e de mobilização (Alvarez, 2014). Também por isso, o feminismo contemporâneo não pode ser tratado em termos dicotômicos, como é o caso da separação muito utilizada entre natureza e cultura, técnica e o social, o sujeito e o objeto e, mais propriamente no caso citado anteriormente, entre um mundo on line e um off line. A ênfase sobre o caráter ficcional dessas dicotomias, sugere que na realidade, elas obedecem a uma pragmática metodológica em que servem como "metáforas úteis" estruturantes do discurso científico e da metafísica de nossa própria cultura (Strathern, 2006).

Seguindo essa linha de pensamento, o objetivo geral deste artigo é compreender através de descrição e análise de algumas manifestações significativas da internet o papel do ambiente web como locus de ação e reflexão de grupos feministas na construção de uma nova epistemologia do conhecimento feminista, mais reticulada, fluida e multivariada - e não mais pautada em uma cisão entre categorias estanques situadas entre um conhecimento "acadêmico oficial" e um conhecimento "pragmático militante",

entre artigos, teses e dissertações, sobre o uso das redes sociais digitais (Vermelho et alii, 2014). Sobre outras temáticas envolvendo a relação entre jovens e o uso de redes sociais, ver Lima e Santos (2012); sobre juventude rural e redes sociais; sobre culturas juvenis e internet, ver Garbin (2003).

2 A atriz Emma Watson, desde que proferiu um discurso feminista para a Campanha He For She, em 2014, para a ONU, não só tem se assumido como tem sido reconhecida como uma mulher eminentemente feminista. Mais recentemente, em fevereiro de 2017, na cerimônia do Oscar 2016, Lady Gaga cantou uma música até então inédita sobre abuso e assédio sexual. 
ou entre um conhecimento que se dissemina "para dentro" $e$ "para fora" dos espaços virtuais (Rifiotis, 2016).

Em primeiro lugar, será discutida a relação histórica entre mulheres e redes sociais e o conjunto de discursos e manifestações feministas que eclodiram a partir de 2015 no Brasil entre as ruas e as redes sociais. Em seguida, é traçado um panorama do "feminismo cibernético", articulando grupos de discussão do Facebook e blogs da internet. Para tanto, considera-se um fenômeno que parece ser constitutivo do conhecimento feminista que ora se dissemina no espaço web: a segmentação bem marcada nesses espaços em "vertentes" (liberal, interseccional, marxista, queer e radical), que competem entre si, sobretudo no que tange à busca de entendimento por uma ontologia de gênero.

A justaposição desses dois campos discursivos (primeiro, a eclosão de uma práxis feminista em 2015 e segundo, as classificações de vertentes no espaço virtual que perfazem uma espécie de "lógica totêmica feminista") ancora a noção descrita por Alvarez (2014), de campo discursivo de ação, que para além de uma noção monolítica do movimento feminista, opera com uma dinâmica que extrapola a sociedade civil e se constrói por meio de um emaranhado de interlocuções, em que as redes são constituídas por interações comunicativas. Os campos discursivos de ação,

se articulam discursivamente através de linguagens, sentidos, visões de mundo pelo menos parcialmente compartilhadas, mesmo que quase sempre disputadas, por uma espécie de gramática política que vincula as atoras/es que com eles se identificam (Alvarez, 2014:19).

A autora identifica três movimentos decisivos na trajetória do feminismo no Brasil. O primeiro seria um movimento de "centramento", que estabelece o feminismo como uma categoria monolítica durante a década de 70; o segundo, um momento de mainstreaming (ou "descentramento") e pluralização dos feminismos entre as décadas de 80 e 90; e por fim, o movimento 
atual, a partir dos anos 2000, em uma dinâmica de sidestreaming, fluxo horizontal dos discursos e práticas feministas plurais entre os mais diversos setores na sociedade civil, resultando em uma multiplicação de campos feministas (Alvarez, 2014).

É nesse terceiro momento que a internet emerge como ponto referencial e constitutivo de redes e pontos de contato entre grupos e organizações feministas, criando "outras redes de comunicação a partir das apropriações da atividade prosumer como instrumento de ação politica e recurso de identificação" (Ferreira, 2015: 208). Os fenômenos aqui analisados são pontos de contato e nós constitutivos desse campo discursivo de ação: blogs, páginas e grupos de discussão do Facebook, vídeos do youtube, sites de notícias, postagens de influenciadores digitais, todos se articulam em uma dinâmica reticular muito especifica desse "ciberfeminismo social" (Boix; Miguel, 2013) através da troca e da discussão de conteúdos.

A capilaridade (aqui proposta como uma das principais características do campo discursivo de ação em análise), também evoca a imagem do éclat/éclatement/éclater, termos propostos por Lévi-Strauss (1985) quando percorre, em francês, as trilhas de significação que ligam dezenas de mitos de dezenas de povos do sul ao norte das Américas. Embora, em português, o campo semântico da família dos éclats jamais atinja o sentido ao qual se propõe (tendo que ser desdobrado em "brilhos", "lascas", "estilhaços", "gargalhadas", "explosões" e outros termos), sabemos que ele alude a própria lógica do pensamento mítico. ${ }^{3}$ Isso significa que os mitos não devem ser analisados de forma linear; seus componentes, ao serem desagregados, são intercambiáveis no mito e de mito para mito. Portanto, diferente de estilhaço, termo que para nós está muito associado à perda, para Lévi-Strauss (2004), os mites en éclat, são um processo caleidoscópico no qual os elementos, apesar da perda (e da impossibilidade de se voltar ao referente original), são restituídos

3 Em sua tradução dos Mitologicas I, Perrone-Moisés nos alerta sobre o "vazamento" de sentidos deste campo semântico (Lévi-Strauss, 2004). 
em novas totalidades por meio de readaptações e combinações. De forma análoga, veremos que os "feminismos" que percorrem os itinerários entre as redes $e$ as ruas combinam elementos presentes e passados (teorias, práticas, citações) que embora possam remeter a uma versão "original", jamais a alcançam, visto que qualquer que seja ela, trata-se apenas de outra versão do mito. ${ }^{4}$

\section{Entre as redes e as ruas: movimentações do campo discursivo de ação feminista}

Essa nova consciência feminista que emergiu nos últimos tempos é um fenômeno sem precedentes e está relacionada às redes eletrônicas, que ofereceram uma nova dimensão à luta e à perspectiva feminista (Miguel; Boix, 2013). Se durante todas as três ondas do feminismo, o movimento dependeu de que as mulheres se organizassem em espaços diversos presencialmente, a partir dos anos 90 a cultura digital possibilitou que as coisas se dessem de forma mais generalizada e pulverizada se tornando, ela mesma, objeto de uma nova epistemologia feminista, que foi chamada de ciberfeminismo. Tratou-se de um movimento estético e político orientado pela popularização das tecnologias digitais que renovou o debate feminista, questionando as desigualdades de gênero através das relações das mulheres com a ciência, a tecnologia e a cultura eletrônica.

Embora o ciberfeminismo tenha se alimentado de diversas fontes de inspiração artísticas como o movimento ciberpunk, o Manifesto Ciborgue, de Donna Haraway (1995), é apontado como seu propulsor. Por isso, no ciberfeminismo, duas das principais abordagens do Manifesto Ciborgue se desdobram ao longo de duas linhas temáticas. Em primeiro lugar, a quebra de binarismos proposta por Haraway (1995) se desdobraria através de reflexões sobre as representações do feminino nas narrativas e histórias de

${ }^{4}$ Meus agradecimentos sinceros ao colega, o prof. Daniel Alves, que apontou a similitude das categorias aqui analisadas com o conceito de Lévi-Strauss. 
ficção, as possibilidades de descorporificação, da abolição/superação dos gêneros, e da hibridização entre organismo e máquina. Essa abordagem se alinharia mais a um "ciberfeminismo radical" praticado pelo grupo australiano VNS Matrix ${ }^{5}$, mais atento à questão da mulher e à desconstrução das assimetrias de gênero e do corpo feminino (Boix; Miguel, 2013).

A segunda abordagem tem sido considerada mais liberal $e$ estaria atenta às contradições da relação entre as mulheres e a informática, bem como ao seu posicionamento no mercado de trabalho, o sistema que Haraway (1995) chamou de "informática da dominação". ${ }^{6}$ Nele, a situação real das mulheres é definida por sua integração em sistema econômico no qual, ao mesmo tempo em que se tornam as principais provedoras da família, também emergem como a classe trabalhadora ideal em um regime caracterizado pelo desemprego estrutural, a precarização, a exploração e a instabilidade salarial. Dentro disso, o ciberfeminismo tentava compreender o que explicaria a prevalência masculina nas profissões de informática (principalmente nos altos escalões), considerando que as mulheres sempre foram detentoras de um saber científico respaldado pelas capacidades de observação e reflexão impostas pela função de nutriz (Miguel; Boix, 2013), e protagonistas de um "imaginário social das redes" - primeiro dominando os teares, e depois como programadoras ainda nos áureos tempos da informática (Plant, 1999).

${ }^{5}$ O VNS Matrix era um coletivo feminista formado por artistas e ativistas, nascido em Adelaide, na Austrália, em 1990, responsável pela publicação em 1991 do Manifesto Ciberfeminista, em homenagem a Donna Haraway. Embora de difícil visualização, diversos trabalhos do VNS Matrix buscam inverter $e$ desconstruir estereótipos, como é o caso do projeto All New Gen (de 1993), que trata da questão das mulheres na cultura dos jogos (Lemos, 2009:72).

${ }^{6}$ O ciberfeminismo liberal seria representado pelo Old Boys Network (Boix; Miguel, 2013), um coletivo surgido em 1997, na Alemanha, durante a I Internacional Feminista, cujo objetivo era dar suporte às carreiras individuais de seus membros, tendo como principal preocupação a construção de espaços de experimentação, comunicação $e$ ação, dando corpo a discussões críticas sobre as novas mídias e a análise sobre as relações entre gênero e tecnologia. 
Sustentado pela relação entre feminismo e tecnologia, emergiu a partir dos anos 2000 um tipo de "ciberfeminismo social" (Boix; Miguel, 2013) que reúne interesses teóricos e práticas plurais, cujas análises recaem sobre o papel das mulheres na história da ciência e da informática; os usos da internet, a inclusão digital e seu papel da socialização de gênero; o uso estratégico das redes sociais no movimento feminista, etc. No bojo desse debate, tem sido apontada a persistência de uma "fratura tecnológica de gênero", referente à hegemonia masculina no circuito tecnológico (Nathanson, 2013). Embora essa desvantagem estrutural de gênero seja visível na participação de mulheres em funções ligadas aos espaços decisórios no mundo high tech, os dados revelam outra situação em relação aos usos sociais das tecnologias digitais. Mundialmente, a diferença de gêneros em termos de acesso a internet é de 2,2\% de homens a mais que mulheres. ${ }^{7}$ Contudo, no Brasil, embora o número de usuários do sexo masculino seja ligeiramente maior que o número de usuárias $(37,5 \%$ de mulheres em relação a $38 \%$ de homens em 2009), esse percentual tem crescido em maior velocidade (Nathanson, 2013).

Tal fenômeno se desdobra na relação entre mulheres $e$ mídias sociais. Dados de uma pesquisa feita em 2013 revelam que mulheres seriam "mais propensas" ao uso de redes sociais do que os homens; entre elas, o Facebook, o Instagram e o Pinterest seriam os mais utilizados, perfazendo uma diferença de $8 \%$ a mais no uso do que os homens. ${ }^{8}$ Em relação à América Latina, uma recente pesquisa revela que as mídias sociais são a categoria que mais consome horas on line por mês, sendo que o maior percentual de usuários se concentra no Brasil $(42 \%)$, onde as

7 Pesquisa realizada pela comscore intitulada "Futuro Digital Latinoamerica 2013" [https://www.comscore.com/lat/Insights/Presentations-andWhitepapers/2013/2013-Latin-America-Digital-Future-in-Focus - acesso em: 06 ago. 2019].

8 O único site mais utilizado por homens é o Reddit com uma diferença de 4\% [http://www.pewresearch.org/fact-tank/2013/09/12/its-a-womans-social-mediaworld/ - acesso em: 10 abr. 2017]. 
mulheres constituem a maior quantidade de acesso às redes sociais $(58,2 \%){ }^{9}$

Isso explica em parte o alargamento do campo discursivo de ação do feminismo nos últimos anos e sua relação direta com a participação das gerações mais recentes. Trata-se de um processo recente e gradual de institucionalização no cenário brasileiro (Facchini; França, 2011), cuja expansão teria se iniciado a partir da década de 90, quando o feminismo começou a se expandir para além dos encontros nacionais e internacionais, capilarizando-se em redes e fóruns locais e regionais, pois era interesse das ONGs a aproximação e a formação de novas militantes ao movimento (Zanetti, 2011).

A constituição de espaços de atuação às margens das formas institucionais reconhecidas indica certa recusa às formas de organização política características das gerações feministas anteriores (Gonçalves; Pinto, 2011). A essa recusa, somam-se outras, também de caráter geracional: a incorporação teórica, conceitual e epistemológica de concepções consideradas "ultrapassadas" ou mesmo a prática política, que não deita raízes em um movimento considerado monolítico, embrutecido $e$ burocratizado. E assim, seja readequando conceitos, refletindo epistemes ou reivindicando velhas categorias a serem usadas junto às novas, o feminismo se capilariza em diversos formatos $e$ tendências, ampliando consideravelmente a participação de mulheres em todos os seus recortes $e$ interseções possíveis. Por esses motivos as novas plataformas de comunicação são tão atraentes aos olhos desta nova geração militante.

O fato é que, no período de 2001 a 2010, houve um crescimento de $10 \%$ no contingente de brasileiras que se considera feminista, sendo as mulheres jovens (entre 15 e 34 anos) as que mais se declaram como tal (Sorj; Gomes, 2014). Nessa cronologia, o

9 "O panorama das redes sociais na América Latina" da comscore [http://www.comscore.com/por/Imprensa-e-eventos/Apresentacoes-edocumentos/2017/O-Panorama-das-Redes-Socias-na-America-Latina - acesso em: 06 ago. 2019]. 
intervalo de 2011 a 2014 parece ser o período de agregação desse campo discursivo de ação em torno da internet no Brasil, coincidindo com a popularidade e o crescimento do Facebook entre os brasileiros. ${ }^{10}$ Dentro disso, a questão da autonomia sobre o próprio corpo emerge como pauta central na reflexão feminista cibernética, se articulando a marchas e protestos feministas, cuja visibilidade agora começa a fazer parte do cotidiano das usuárias. A Marcha das Vadias é emblemática nesse sentido, sendo a primeira manifestação brasileira que teve como marca o caráter reticular, através de blogs e redes sociais (Sorj; Gomes, 2014).

Embora seja cedo para afirmar, tudo parece indicar que de 2015 até o momento estamos diante de um movimento de eclosão do campo discursivo de ação feminista no Brasil. É quando ele adquire um formato mais fractal, isto é, se reproduz sob escalas diferentes, mas invariantes, de forma contínua no espaço e nas subjetividades, perfazendo uma espécie de Zeitgeist. Nesse momento, a internet começa a ocupar um papel muito semelhante ao dos grupos de consciência nos Estados Unidos na década de 70 , se consolidando como um espaço facilitador de trocas, onde as mulheres (mesmo as que não reivindicam para si uma identidade feminista) identificam, compartilham e nomeiam experiências comuns.

Nesse processo, as campanhas cibernéticas tiveram um papel fundamental como estratégias de ação e reconhecimento do campo discursivo de ação feminista. A campanha que teve como hashtag \#meuprimeiroassédio (aqui, a alusão a uma famosa campanha publicitária da década de 80 sobre o primeiro sutiã é bastante significativa) começou espontaneamente no Twitter $e$ teve como estopim as mensagens de teor sexual a respeito de uma menina de doze anos, participante de um programa de TV, trazendo à luz histórias de perseguição, assédio, estupros, até

\footnotetext{
${ }^{10}$ Fonte: "O panorama das redes sociais na América Latina" da ComScore: http://www.comscore.com/por/Imprensa-e-eventos/Apresentacoes-edocumentos/2017/O-Panorama-das-Redes-Socias-na-America-Latina acesso em $\underline{10 / 04 / 2016 .}$
} 
então mantidas em segredo por mulheres que se sentiam envergonhadas e culpadas. A campanha \#meuamigosecreto, marcava o Dia Internacional da Não Violência contra as Mulheres, estimulando mulheres a compartilharem suas histórias $e$ experiências, alertando para atitudes machistas naturalizadas no cotidiano. $^{11}$

Seguidas dessas, outras campanhas virtuais surgiram. As campanhas Chega de Fiu Fiu e Vamos Juntas? reforçaram a questão da busca pela autonomia feminina nos espaços públicos. A primeira deu origem ao site Think Olga (um importante veículo de informação feminista) e se iniciou com uma pesquisa sobre as cantadas que as mulheres ouvem nas ruas, tendo como resultado o fato de que das 8 mil entrevistadas em diversos estados brasileiros, $99,6 \%$ relataram já ter passado por situações constrangedoras. Após isso, vários dados sobre a pesquisa foram disponibilizados na internet, dando vitalidade a um tema pouco tratado até então na mídia tradicional. A segunda, através de uma página do Facebook estimula as mulheres a fazerem companhias umas às outras nas ruas, gerando uma sensação de segurança. A campanha tem como objetivo a criação de um aplicativo que mapeie locais perigosos onde houve assédios, crie alertas $e$ permita que desconhecidas próximas possam se encontrar. ${ }^{12}$

Nesse cenário é importante que as inflexões desse campo discursivo de ação sejam pontuadas em sua relação estreita com as transformações radicais no campo da política brasileira no período de 2013 a 2016, através de múltiplos tensionamentos ocasionados por uma série de rupturas, tais como:

\footnotetext{
${ }^{11}$ Pouco anterior a essas, a campanha \#EuNãoMereçoSerEstuprada se transformou em um protesto virtual de grande escala, tendo se iniciado com uma jornalista que escreveu a frase em seu corpo seminu, divulgando a foto, um dia após a divulgação de uma pesquisa do Instituto de Pesquisa Econômica Aplicada - IPEA que afirmava que $65 \%$ dos brasileiros acreditam que mulher que mostra o corpo merece ser violentada.
}

${ }^{12}$ A página da campanha de arrecadação para o aplicativo [https://www.catarse.me/vamosjuntas - acesso em: 20 abr. 2016]. 
-A emergência do segundo mandato de uma presidente de esquerda (Dilma Roussef) e seu posterior impeachment em 2016, articulado por setores da extrema direita, que então buscava a retomada do poder através do conluio entre Câmara dos Deputados, Senado Federal e o Poder Judiciário; ${ }^{13}$

- O ataque a direitos já conquistados pelas mulheres, trabalhadores e minorias rompendo com os princípios de laicidade do Estado e detendo uma série de avanços em direitos humanos; ${ }^{14}$

- Uma ofensiva contra o aborto no Congresso Nacional, que através de projetos de leis e estatutos ${ }^{15}$ tem dificultado seu acesso, penalizado mulheres e atores envolvidos no processo (profissionais da saúde) e revogado direitos já conquistados - o aborto terapêutico em caso de anencefalia, gestação inviável ou estupro; ou ainda, o acesso a métodos contraceptivos como a pílula do dia seguinte. ${ }^{16}$

Junto à figura do deputado Eduardo Cunha (então presidente da Câmara dos Deputados, autor de diversas delas), essas medidas se tornaram expoentes de uma anti-democracia

\footnotetext{
${ }^{13}$ A composição do Congresso Nacional neste período foi considerada a mais conservadora desde a ditadura civil-militar de 1964 e expressa sua política reacionária a partir da articulação da intitulada Bancada BBB (Boi-Bala-Bíblia) que dá suporte a ataques aos direitos trabalhistas $e$ ameaça grupos historicamente oprimidos.

${ }^{14}$ Emblema deste retrocesso foi extinção dos Ministério das Mulheres, da Igualdade Racial, da Juventude e dos Direitos Humanos. No âmbito dos direitos da população LGBT, temos como exemplo a aprovação da preocupante PL6583/2013 que se pressupõe a legitimidade da família através de núcleo formado por apenas pai, mãe e filhos.

${ }^{15} \mathrm{O}$ Estatuto do Nascituro prevê pena de detenção de um a três anos para quem realizar pesquisa com célula-tronco (PL 489/2007); concede pensão à mãe que mantenha a criança nascida de gravidez decorrente de estupro (PL 3748/2008), além de aumentar as penas para prática de aborto. Fontes: "Os perigos do Estatuto do Nascituro". Carta Maior: disponível em http://www.cartamaior.com.br/?/Editoria/Primeiros-Passos/Os-perigos-do-

Estatuto-do-Nascituro/42/28055. Acesso em 20/04/2017.

${ }^{16}$ Respectivamente os Projetos de Lei: 7235/2002, 5364/2005, e 1413/2007

Disponível para consulta em: http://www2.camara.leg.br/Acesso em 20/04/2017.
} 
golpista. ${ }^{17}$ Sob a hashtag \#MulheresContraCunha $e$ \#PilulaFicaCunhaSai, milhares de mulheres se organizaram pelas redes sociais e foram as ruas das principais capitais brasileiras três vezes em 2015. ${ }^{18}$

Esse novo Zeitgeist foi captado com certo entusiasmo $e$ ganhou a alcunha de "Primavera Feminista", uma analogia a "Primavera Árabe", que da mesma maneira, se caracterizou justamente pelo uso maciço das mídias e redes digitais como instrumentos de conscientização e mobilização. ${ }^{19} \mathrm{Em}$ diversas mídias, 2015 foi proclamado o ano do Feminismo, mostrando o alcance $e$ o papel da internet nesse novo processo de conscientização: a cada nova hashtag, crescia o número de acessos em busca de mais informações. ${ }^{20}$

${ }^{17}$ O Projeto de Lei no 5069/2013 de Eduardo Cunha reforçava a criminalização do aborto e descaracterizava a Lei de Atendimento à Vítima de Violência Sexual ( $N^{\circ}$ 12.845/2013), exigindo que, para ser atendida pelo Sistema Único de Saúde (SUS), a vítima teria de comprovar a violência através de exame de corpo de delito e boletim de ocorrência.

${ }^{18}$ Fonte: "Mulheres protestam contra Cunha pela terceira vez em duas semanas", El Pais, $\quad$ Brasil, $12 \quad$ nov. 2015 [http://brasil.elpais.com/brasil/2015/11/12/politica/1447346906 965515.html acesso em: 20 abr. 2017].

${ }^{19}$ A "Primavera Árabe" foi uma onda de protestos e manifestações no Oriente Médio e no Norte da África, em dezembro de 2010, contra o agravamento da situação econômica, a falta de democracia $e$ as tentativas de repressão por parte de governos autoritários. Os protestos fizeram uso das mídias e redes sociais para organizar e sensibilizar a população e compartilharam técnicas de resistência civil em campanhas que envolviam greves, manifestações, passeatas e comícios. Culminou com a derrubada de quatro chefes de Estado há anos no poder (Joffé, 2011).

${ }^{20}$ Site Think Olga, 2015 [http://thinkolga.com/2015/12/18/uma-primavera-semfim/ - acesso em: 29 set. 2016]. 
Imagem 1: Impacto do conhecimento feminista na internet 2014-2015 (Think Olga)

Entre janeiro de 2014 e outubro de 2015, as buscas por "feminismo" e "empoderamento feminino" cresceram $86,7 \%$ e $354,5 \%$ respectivamente.

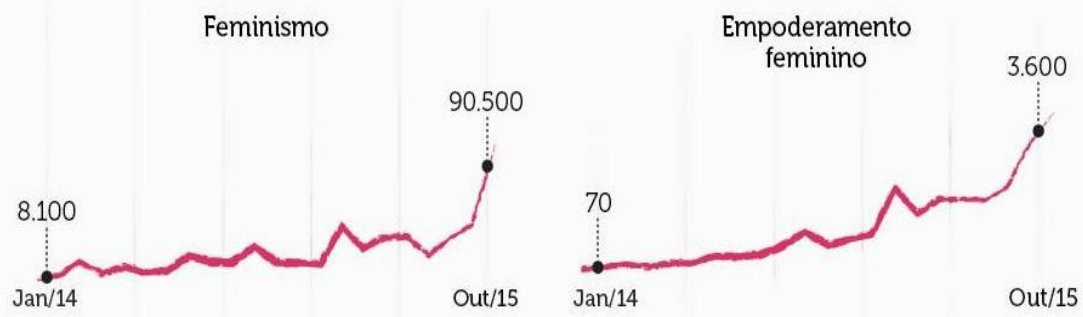

Fonte: Site Think Olga, 2015 [http://thinkolga.com/2015/12/18/uma-primaverasem-fim/ - acesso em: 29 set. 2016].

\section{Conhecimento feminista na era digital}

Os grupos de discussão do Facebook são espaços nos quais os participantes debatem, trocam experiências, compartilham notícias, artigos, pedem ajuda ou simplesmente utilizam-no para o aprendizado, não sendo necessariamente assíduos nas postagens. O elemento chave desses espaços é a "segurança" de seus membros contra a exposição daquilo que publicam ou comentam em outras páginas, sites ou grupos. Os moderadores escolhem sua visibilidade ou ocultação, estabelecendo critérios para a entrada. Dentre as opções, é possível deixá-lo em:

1. Modo público ou aberto, em que é possível visualizar os grupos pelos mecanismos de busca;

2. Modo fechado em que é possível visualizar pelos mecanismos de busca, mas geralmente existem regras e critérios a serem seguidos (barrando a entrada de homens, por exemplo); 
3. Modo secreto: somente participantes visualizam-nos através dos mecanismos de busca; a entrada de novos membros novos é feita somente mediante convite de participantes.

É esse caráter eletivo que diferencia os grupos de discussão de páginas do Facebook. Eles guardam uma vaga semelhança com os blogs da internet quanto às possibilidades de interação entre os membros; contudo, afastam-se deles, em relação ao caráter coletivo da autoria (isto é, qualquer participante do grupo pode fazer postagens e respondê-las) e em relação à dinâmica do fluxo de informações (dependendo do grupo, o volume de postagens é muito alto, dificultando o acompanhamento de determinadas postagens desde o início).

$\mathrm{Na}$ pesquisa de busca de grupos de discussão feministas na rede social, foram usadas as palavras chaves "feminismo" $e$ "feminismos", tendo como resultado um total de 100 grupos de discussão em língua portuguesa. ${ }^{21}$ Destes, apenas cinco são nomeados somente com a palavra "Feminismo" ou "Feminismos". Os demais são nomeados de acordo com outros componentes significativos:

1. Finalidades (objetivo, público): Feminismo para iniciantes, Feminismo em off, Feminismo e fé , Aprenda feminismo;

2. Lugares e instituições de pertença: Feminismo Lavras, Feminismo UFF, Feminismo em Uberlândia;

3. Identidades étnicas, sexuais, de gênero e de grupo social: Feminismo Asiático, Feminismo Gênero, Sex e BDSM, Feminismo Trans 2.0, Feminismo das Pretas;

4. Recortes temáticos e fronteiras (inter)disciplinares: Endometriose e Feminismo, Feminismo e Maternidade, Direito e

\footnotetext{
${ }^{21}$ Nesta pesquisa, portanto, não foram abarcados grupos em que essas palavraschave não constassem em sua nomenclatura, e nem os grupos secretos dos quais a pesquisadora não participa, o que certamente se configura como um desvio metodológico.
} 
Feminismo, Feminismo Filosófico, Feminismo e Política, Feminismo - saúde mental e troca de experiências;

5. Escolas e vertentes de pertencimento: Feminismo Marxista, Feminismo Dialético, Feminismo Radical, Feminismo Libertário, Feminismo Liberal, Feminismo Negro, Feminismo Interseccional.

Dessa tipologia, o interesse incide sobre o quinto item que se refere às vertentes feministas, perfazendo o total de 29 grupos (coluna 2 da Tabela 1). É um percentual significativo, que pode indicar tanto a busca legítima por pertencimento ideológico, quanto uma necessidade de aprofundamento de determinados temas através da perspectiva de vertentes específicas. Mesmo os grupos que não aludem diretamente a uma filiação ideológica, procuram fazê-lo na descrição do grupo, em postagens fixas ou mesmo através da intervenção dos moderadores em determinadas postagens - seja advertindo ou punindo membros que apresentem discursos considerados contrários ao grupo (em alguns grupos, posturas machistas, homofóbicas ou transfóbicas).

\subsection{Vertentes feministas do Facebook}

Buscando descrever, compreender e analisar com a maior precisão possivel as categorias (traduzidas em vertentes feministas) que integram o imaginário e o conhecimento feminista contemporâneo, estabelecemos como critério metodológico o cruzamento entre os resultados da busca por grupos de discussão do Facebook e a tipologia utilizada em blogs da Internet. Tem sido prática comum nos grupos de discussão, que os primeiros contatos de seus participantes com o feminismo procedam de conteúdos de blogs feministas de grande visibilidade. Isso possibilitará a análise dessas categorias como um conjunto de significados próprios do espaço virtual, um discurso êmico mais propriamente dito. 
Os critérios para a escolha desses blogs se pautaram nos parâmetros do sistema de buscas do Google, considerando sua precisão. ${ }^{22}$ Ao buscar no Google os termos Tipos de Feminismo ou Vertentes do Feminismo, sem aspas, temos resultados similares. Em ambos os casos, o buscador nos direciona a uma gama de blogs, portais feministas e sites elencados de forma semelhante, que tematizam o assunto. Sendo o foco o primeiro tipo de veículo, elencamos os quatro primeiros resultados obtidos.

${ }^{22} \mathrm{O}$ Google analisa mais de 100 critérios para o ranqueamento, dentre os quais: a) Relevância da página usada nos termos de busca; b) Padrões de acessibilidade, como o uso da linguagem HTML e títulos das páginas; c) Autoridade no assunto ao qual a página se destina; d) O conteúdo dos links na página (se são relevantes); e) Palavras-chave relevantes para o tema buscado. Vale notar, que quando os termos são digitados com aspas, os resultados, além dos critérios de busca do Google, obedecem a uma cronologia na qual o conteúdo mais atual (mas não necessariamente mais relevante) do tema aparece logo nos primeiros resultados. Para os fins deste trabalho, interessa a relevância da página entre milhares possíveis. Fonte: "Porque um site fica em primeiro lugar no google?" [http://www.conversion.com.br/blog/por-que-um-site-fica-emprimeiro-lugar-no-google/ - acesso em: 02 jan. 2017]. 
Tabela 1. Vertentes feministas segundo blogs

\begin{tabular}{|c|c|c|}
\hline $\begin{array}{l}\text { Blogs por ordem de } \\
\text { visibilidade no Google }\end{array}$ & Titulo e autor do artigo & Tipologia elencada \\
\hline 1.Brasil Post & $\begin{array}{l}\text { Aguiar, Ione. "Qual é o } \\
\text { seu feminismo? Conheça } \\
\text { as principais vertentes do } \\
\text { movimento"23 }\end{array}$ & $\begin{array}{l}\text { 1.Feminismo negro } \\
\text { 2.Feminismo interseccional } \\
\text { (ou pós moderno) } \\
\text { 3.Feminismo radical } \\
\text { 4.Feminismo liberal }\end{array}$ \\
\hline 2. Medium & $\begin{array}{ll}\text { Lemos, Kamyla. } & \text { "O } \\
\text { movimento feminista } & e \\
\text { suas vertentes"24 } & \end{array}$ & $\begin{array}{l}\text { 1.Feminismo radical } \\
\text { 2.Feminismo negro } \\
\text { 3.Transfeminismo } \\
\text { 4.Feminismo liberal } \\
\text { 5.Feminismo interseccional }\end{array}$ \\
\hline 3. Portal Geledés & $\begin{array}{l}\text { Aguiar, Ione. "Qual é o } \\
\text { seu feminismo? Conheça } \\
\text { as principais vertentes do } \\
\text { movimento"25 }\end{array}$ & Idem 1 \\
\hline 4. Pandora Livre & $\begin{array}{lr}\text { Nobrega, } & \text { Mariana. } \\
\text { "Entenda os } & \text { diferentes } \\
\text { feminismos"26 } & \end{array}$ & $\begin{array}{l}\text { 1.Feminismo Liberal } \\
\text { 2. Feminismo Marxista } \\
\text { 3. Feminismo Radical } \\
\text { 4. Feminismo Interseccional } \\
\text { 5. Feminismo Queer }\end{array}$ \\
\hline
\end{tabular}

A tipologia das vertentes tende a variar em cada blog, como no caso do "feminismo negro" e do "interseccional", que podem aparecer justapostos (o segundo considerado originário do primeiro) ou separados, porém não totalmente divergentes (item 1, Tabela 1). ${ }^{27}$ Interseccionalidade tem sido considerado um

\footnotetext{
${ }^{23}$ [http://www.brasilpost.com.br/2015/06/14/feminismo-correntesfeministas n 6788376.html - acesso em: 02 out. 2016].

${ }^{24}$ [https://medium.com/@kamyllalemos/o-movimento-feminista-e-suas-vertentes3492875e162a\#.nysmlm4m1 - acesso em: 02 out. 2016].

${ }^{25} \mathrm{O}$ artigo é uma reprodução do conteúdo do blog elencado em primeiro lugar nesta pesquisa, procedimento comum em blogs e sites da internet.

${ }^{26}$ http://pandoralivre.com.br/2015/08/26/entenda-os-diferentes-feminismos/ acesso em: 02 out. 2016.

${ }^{27} \mathrm{O}$ site Blogueiras Negras, um veículo de grande relevância sobre questões feministas e étnico raciais defende o uso do termo Feminismo Interseccional para o Feminismo Negro contemporâneo e aponta a interseccionalidade como uma
} 
importante instrumento crítico sobre a heterogeneidade $e$ a importância política da categoria mulher (Piscitelli, 2002; Nicholson, 2000) e parece ser o caso de um conceito exportado diretamente da produção acadêmica para a o mundo virtual. Seu surgimento remonta a produção de acadêmicas feministas negras da década de 80 e 90 nos EUA para se referir a opressões que se intersectam, como sexualidade (no caso de gays e lésbicas), gênero (no caso pessoas trans), classe social e raça. Contudo, a depender do contexto de uso tem sido apropriado como um conceito, uma ferramenta heurística ou uma teoria. Devido a essa polissemia, o Feminismo Interseccional emerge diversas vezes como englobante de outras categorias (negros, populações LGBT), e feminismos (Feminismo Negro e feminismos "Queer", "Transfeminismo) ou simplesmente como sinônimo do Feminismo Pós Moderno (blogs 1 e 3).

A coluna 3 (Tabela 2) remete aos resultados da busca refinada por grupos de discussão feministas no Facebook alinhados a vertentes em que foram utilizados os mesmos termos de busca elencados na Tabela 1 (feminismo + vertente). $\mathrm{O}$ objetivo foi abranger os grupos que não necessariamente descrevem a vertente de pertencimento no título.

$\begin{array}{lcccc}\text { categoria } & \text { ainda } & \text { em } & \text { construção. } & \text { Fonte: } \\ \text { http://blogueirasnegras.org/2015/09/29/feminismo-interseccional-um-conceito- }\end{array}$

em-construcao/ - acesso em: 03 out. 2016. 
Tabela 2. Pesquisa por grupos de discussão feministas no Facebook

\begin{tabular}{lcccc}
\hline \multicolumn{4}{c}{ Critérios de Busca } \\
\hline 1.Vertentes & $\begin{array}{c}\text { 2. Busca geral } \\
\text { pelo termo } \\
\text { "Feminismo" }\end{array}$ & $\begin{array}{c}\text { 3. Busca Refinada pelo } \\
\text { termo feminismo }+ \\
\text { vertente/ numero total } \\
\text { de membros }\end{array}$ \\
\hline $\begin{array}{l}\text { Feminismo interseccional/ pós } \\
\text { moderno }\end{array}$ & 6 & 6 & 10.069 \\
\hline Feminismo libertário ou liberal & 9 & 9 & 4.384 \\
\hline Feminismo LGBT*/ trans /queer & 4 & 8 & 1.778 \\
\hline Feminismo radical & 7 & 18 & 5.827 \\
\hline Feminismo marxista/ materialista. & 3 & 6 & 2.304 \\
\hline Total & 29 & 47 & \\
\hline
\end{tabular}

Observa-se que além da maioria dos grupos de discussão terem dobrado seu número após a busca refinada, a vertente do feminismo interseccional é mais volumosa em termos de participantes (o maior grupo dessa vertente ultrapassa os 7000 membros, sendo que os demais grupos não ultrapassam os 2000 membros). Ao mesmo tempo, possui um baixo número de grupos de discussão em relação as demais - perdendo apenas para a busca geral em que os grupos ligados as vertentes do Feminismo LGBT/trans/queer e de Feminismo marxista/materialista aparecem num total de 4 e 3, respectivamente (coluna 2, Tabela 2). Isso pode representar certa coesão de ideias e posicionamentos, que aparece, sobretudo quando se compara ao ranqueamento da vertente do Feminismo Radical. Nesse caso, nota-se o inverso, isto é, um baixo volume de participantes em relação ao total do Feminismo Interseccional (pouco mais da metade) e o maior número de grupos de discussão entre todos os demais (18, como se vê na coluna 3, Tabela 2). Alvo predileto de muitas críticas no espaço virtual por parte de outras vertentes, o feminismo radical se inscreve em uma contradição: seu crescimento se dá na mesma medida em que seu caráter pejorativo se dissemina entre outras 
vertentes, e de modo mais geral, em todo espaço virtual. ${ }^{28}$ Diversas hipóteses norteiam esse fenômeno. Em primeiro lugar, a curiosidade e o interesse de participantes de grupos aliados a outras vertentes em conhecer o lado "oponente". Por outro lado, pode ser que isso seja parte de uma "trajetória epistemológica", através da qual os agentes se moveriam em busca de explicações de caráter mais estrutural na mesma medida em que se distanciam das explicações mais ontológicas baseadas nas identidades. ${ }^{29}$ Também não se pode deixar de considerar a possibilidade de haver numerosos conflitos internos entre os grupos de discussão aliados a vertente do feminismo radical, o que levaria a essa cisão entre 18 grupos. São muitas as hipóteses possíveis que norteiam esse fenômeno, assim como a adesão massiva à vertente do feminismo interseccional, mas por hora, elas deverão fazer parte de uma agenda para que este fenômeno seja mais bem explorado em trabalhos futuros.

Nos itens seguintes (de 3.1.1 a 3.1.5) é apresentada uma breve descrição do conteúdo dessas vertentes (ou traços do feminismo, pois ora se fundem, ora se justapõem) buscando os elementos êmicos do universo pesquisado. Procurou-se delinear o imaginário feminista cibernético buscando narrativas sobre: as origens da vertente; causas que reivindica; objetivos em termos socioculturais (o projeto, mais propriamente dito); e ícones e ou teóricos mais citados nas discussões. A configuração e a escolha das vertentes foram pensadas a partir de dois critérios. Primeiro, a recorrência com que cada vertente apareceu tanto na pesquisa de blogs (Tabela 1), quanto na pesquisa de grupos de discussão feministas do Facebook (Tabela 2). Segundo, a centralidade que essas categorias parecem ocupar no imaginário feminista cibernético: Feminismo Liberal, o Feminismo Radical, o

\footnotetext{
${ }^{28}$ Sobretudo pelo caráter essencialista a respeito da construção de gênero, como será tratado.

${ }^{29}$ Ambas as explicações são possíveis e já foram contempladas em pesquisa preliminar por membros de um grupo sobre feminismo radical quando perguntados porque e como se aliaram a essa vertente.
} 
Feminismo Negro, o Feminismo Interseccional, o Feminismo de que se agrupa no eixo LGBT/Queer/Trans e o Feminismo de orientação Marxista/ Socialista. ${ }^{30} \mathrm{O}$ conteúdo de cada uma delas foi extraído das descrições de vertentes nos blogs elencados segundo a Tabela 1 deste texto. Embora não seja a intenção explorar neste artigo os significados dessas singularidades nos processos de apagamento e/ou de destaque a uma ou outra vertente, bem como seu caráter político, ideológico $e$ epistemológico, reconhecemos a importância de se pontuar esses elementos como constitutivos de futuras reflexões sobre a epistemologia do conhecimento no espaço virtual. Por fim, as observações analíticas do autor são apontamentos gerais sobre os contornos e feições que esse conteúdo tem tomado em termos mais gerais nas redes sociais e foram traçados a partir: 1 . da própria epistemologia feminista; 2. da observação participante nos grupos de discussão feministas; 3 . da análise do discurso de feministas que mantêm perfis no Facebook e que se auto definem como aliadas a uma ou outra vertente; e 4 . da análise de páginas e comunidades da rede social.

\subsubsection{Feminismo Liberal}

Origens: Iluminismo e Revolução Francesa. Causas: Emancipação feminina através da liberdade, do direito a propriedade, da educação, do direito a resistência contra a opressão e a participação política (Pandora). Objetivos: Igualdade entre todos através da radicalização do projeto igualitário Iluminista. Mais atualmente, o feminismo liberal lutaria pela ascensão de mulheres a posições em instituições como o Congresso, os meios de comunicação $e$ as lideranças de empresas (Brasil Post). Ícones mais citados: Olympe de Gouges, Mary

\footnotetext{
${ }^{30}$ Este último, embora tenha aparecido em apenas um dos blogs na Tabela 1, apareceu sob denominações diferentes, totalizando seis na busca por grupos de discussão do Facebook (Tabela 2).
} 
Woolstonecraft (Pandora), Naomi Wolf, Betty Friedan, John Stuart Mills, Beyoncé, Emma Watson.

Observações analíticas do autor: 1. Possui um caráter reformista; 2. Defende a incorporação dos homens em sua participação; 3. Tem como princípio a liberdade de escolha, inclusive sobre a questão das identidades, da indústria do sexo (prostituição e pornografia) e dos padrões estéticos; 4. Narrado como sendo o extremo oposto do feminismo radical; 5. Embora não seja considerado muito popular no Brasil, na internet tem se popularizado antinomicamente ao RadFem (Feminismo radical) como "LibFem".

\subsubsection{Feminismo Radical}

Origens: Décadas de 60 e 70, a partir das obras de Shulamith Firestone e Judith Brown (Brasil Post) e, anteriormente, Simone de Beauvoir como precursora das bases para a configuração do conceito de gênero, usado nos feminismos posteriores. Causas: A raiz da dominação masculina estaria no patriarcado, nos papéis sociais intrínsecos ao sistema de gênero. $\mathrm{O}$ patriarcado seria um sistema de dominação social pelo sexo, se manifestando no controle dos corpos femininos, especialmente pelo controle da maternidade e da sexualidade das mulheres através da família e no que fosse relacionado à reprodução, $e$, posteriormente, alcançaria os níveis político, econômico e jurídico. Objetivos: Expor o funcionamento do patriarcado $e$ as experiências de opressão em comum vividas pelas mulheres; a conscientização das mulheres sobre o caráter coletivo de suas opressões; a construção de ferramentas de transformação do mundo; dissolução do sistema de gênero e dos papéis fortemente arraigados a ele. Ícones: Simone de Beauvoir, Shulamith Firesthone, Sheila Jeffreys, Kate Milett, Andrea Dworkin.

Observações analíticas do autor: 1. Nos últimos anos, essa vertente tem sido denominada pelas jovens de "radfem", adaptando os argumentos clássicos sobre a socialização feminina a questões mais atuais. 2. Essa vertente recorre a posições 
construcionistas e essencialistas, atribuindo um caráter estrutural à socialização de gênero advinda do sexo atribuído biologicamente. Gênero seria construído socialmente, mas decorreria dos significados atribuídos ao sexo biológico/anatomia. Dentro dessa perspectiva, a performance de gênero é vista como um aspecto negativo da socialização feminina, o qual não deveria ser reforçado através dos estereótipos de gênero. 3. "Ser mulher" ou "homem" não são apenas questões ontológicas ou posições subjetivas, mas atribuições que denotam regras sociais e no caso das mulheres, opressões estruturais (inclusive a própria identificação com um gênero seria uma delas). 4. Essa retomada de um determinismo biológico, tem servido como pressuposto para que esta seja apontada como uma vertente moralista $e$ passível de alinhamento com os setores mais conservadores da sociedade. 5. Nos grupos de discussão tem sido apontado o desdobramento para subvertentes derivadas, como a Trans Exclusionary Radical Feminists (TERF), isto é, feministas radicais que excluem transexuais. 6. Crítica às estruturas que consideram reforçar o gênero e seus efeitos como a maternidade, a feminilidade, a pornografia e a prostituição. 7. Por ter uma postura mais estruturalista, tem sido apontada como oposta aos feminismos interseccional e liberal, os quais supostamente se alinham a uma perspectiva mais ontológica, subjetiva $e$ voluntarista sobre gênero - dentro disso, caberia às feministas acolherem todas as formas de "ser/sentir-se uma mulher".

\subsubsection{Feminismo Negro}

Origens e fundamentos: Início da década de 20 com a crítica de feministas negras contra a homogeneidade da categoria mulher (Davis, 1981). Para elas, as primeiras manifestações feministas simplificavam excessivamente a condição das mulheres, como se todas tivessem as mesmas vivências e o mesmo histórico social $e$ econômico. Contudo, enquanto movimento fortalecido surge do final dos anos de 1970 conhecido como Black Feminism, cuja crítica se voltou de maneira radical contra o feminismo branco, 
considerado de classe média e heteronormativo. Causas: Presume que a mulher negra, por sofrer uma dupla opressão, não seria representada por outros feminismos, que englobariam apenas a opressão de gênero desconsiderando $e$ invisibilizando as necessidades da classe de mulheres trabalhadoras e de classe baixa, ou seja, as mulheres negras. Objetivos: $\mathrm{Na}$ internet, o feminismo negro tem colocado em debate pautas que supostamente não seriam priorizadas em outros feminismos, como: genocídio da juventude negrae seus impactos sobre as mulheres negras, a intolerância religiosa $e$ a valorização das religiões de matriz africana, relacionamentos inter-raciais e relações afetivoamorosas de mulheres negras, mercado de trabalho, padrões estéticos femininos e a representatividade dos negros na mídia, impacto da violência cotidiana na população negra, etc. Ícones: Angela Davis, Audre Lorde e bell hooks. No Brasil, Lélia Gonzales e Sueli Carneiro.

Observações analíticas do autor: Profundo e intermitente debate entre raça e gênero. Como mencionado, nos grupos de discussão do Facebook e nos blogs pesquisados, o termo "feminismo negro" não tem sido consensual, sendo por vezes a questão racial identificada como uma das diversas interfaces do "feminismo interseccional". Porém, a demarcação de grupos de discussão do Facebook, bem como nas tipologias de feminismos encontradas nos blogs pesquisados, sugere o uso do termo mais propriamente como um marcador politico e ideológico do que uma questão epistemológica.

\subsubsection{Feminismo Interseccional}

Origens e fundamentos: O termo "Interseccional" foi conceitualizado na década de 90 com a obra da jurista afro americana Kimberlé Crenshaw (2002) professora de Direito na UCLA e em Columbia, ao se referir ao estudo de como diferentes estruturas de poder interagem nas vidas das minorias, especialmente das mulheres negras. Objetivos: Os blogs pesquisados são unânimes em afirmar que o feminismo 
interseccional busca "conciliar as demandas de gênero com as de outras minorias, considerando classe social, raça, orientação sexual, deficiência física... São exemplos de feminismo interseccional o transfeminismo, o feminismo lésbico e o feminismo negro". ${ }^{31}$ Ícones: Kimberlé Crenshaw, Patricia Collins (por terem trabalhado e lançado mão do conceito). Mas de modo geral, são utilizadas as mesmas autoras mencionadas na seção dedicada ao Feminismo Negro.

Observações analíticas do autor: Segundo Hirata (2014), embora o uso do termo interseccionalidade tenha se tornado um hit concept e o sucesso alcançado por ele date da segunda metade dos anos 2000, sua origem remonta ao movimento do final dos anos de 1970 que veio se tornar o Feminismo Negro. De acordo com os resultados desta pesquisa (a maior adesão no universo pesquisado), tudo leva a crer que tem se tornado uma das vertentes mais populares. 2. Outra tendência observável no espaço virtual tem sido a dificuldade de se aplicar esse conceito na prática sem que se recaia em uma contraproducente hierarquização de formas de opressão que são, em última análise, imbricadas $e$ intrínsecas umas às outras. Isso provavelmente se deve a um modelo de "soma de opressões", muito presente no imaginário social, incapaz de compreender como essas interconexões se sobrepõem $e$ se influenciam mutuamente dando origem a uma matriz (Collins, 2000). 3. Uma crítica comum a essa vertente por parte do feminismo radical tem sido sua adesão às correntes pósestruturalistas e as teorias queer, que apesar de reconhecerem as estruturas sociais do sistema binário de gênero, recairiam em um individualismo metodológico - ao defender que gênero é identificação ou subjetividade.

\footnotetext{
${ }^{31}$ Cf. http://www.brasilpost.com.br/2015/06/14/feminismo-correntesfeministas_n_6788376.html. - acesso em: 03 de outubro de 2016.
} 


\subsubsection{Feminismo de orientação LGBT/Queer}

Origens e fundamentos: De modo geral, emerge junto à chamada "terceira onda" do feminismo, cujo mais recente desdobramento surgiu no bojo das teorias pós estruturalistas. No Brasil, a tradução e o lançamento do livro Problemas de Gênero (Butler, 2003) impacta de maneira significativa esse processo $e$ coincide diretamente com a emergência da luta política minoritária pelas identidades durante a década de 2000. Causas: Aponta que a categoria "mulheres" é produzida e reprimida pelas mesmas estruturas de poder por meio das quais se busca emancipação. Assim, a aceitação de um sistema binário de gêneros (masculino $e$ feminino) implicitamente indica a relação com um sexo, ignorando categorias fora da matriz heterossexual (Butler, 2003) como drag queens, travestis e transexuais e todas as identidades que não se identificam com a dualidade. Por querer refletir apenas o sexo ou por ele ser restrita, gênero seria opressivo. Objetivos. Seu foco de lutas é a subversão e o rompimento das normas de comportamento sexual e/ou amoroso socialmente prescritas. Na prática, diversas de suas pautas dizem respeito à luta politica pelas identidades LGBT's (como a questão do nome social, o sistema de garantia de direitos, acesso ao sistema de saúde, etc). Icones: Como foi dito, a inspiração teórica tem sido a obra de Butler, porém em outros âmbitos, essa vertente, assim como as demais, tem se encarregado de produzir seu próprio conjunto de ícones, geralmente oriundos da própria internet ou da mídia. Aí se pode incluir desde celebridades nacionais e internacionais (como Madonna), até militantes e ativistas do Facebook.

Observações analíticas do autor: 1. A despeito das diferentes nomenclaturas, os feminismos aliados aos LGBTs teriam como prioridade a inclusão das categorias ininteligíveis dentro da lógica do binarismo sexual (Butler, 2003) através da discussão das pautas especificas, justificando a criação de grupos de discussão feministas exclusivamente voltados a esse público. Também independentemente das diferenças que possam separá-los, os feminismos LGBT aludem a um alinhamento com correntes 
teóricas pós estruturalistas que prescrevem a desconstrução das categorias binarias de gênero (Foucault e Judith Butler são os principais expoentes). 2. Uma das críticas feitas a essa vertente é semelhante a que se faz sobre o Feminismo Interseccional: o fato de supostamente tangenciar a discussão sobre socialização de gênero por certo receio de recair em um determinismo biológico, defendendo que "sentimentos" e "emoções" seriam suficientes para a definição das identidades e de gênero - deslizando para um essencialismo voluntarista.

\subsubsection{Feminismo de orientação socialista/marxista/ materialista}

Origens e fundamentos: Desdobramento crítico das reflexões de Friedrich Engels em $A$ origem da familia, da propriedade privada e do estado, tendo como cerne a visão histórica de que a origem da opressão feminina e da feminização da pobreza estaria no surgimento da propriedade privada e da sociedade de classes, de onde derivariam também o casamento monogâmico, o controle da sexualidade feminina $e$ a invisibilidade do trabalho feminino na esfera doméstica na manutenção do capital. O tema foi trabalhado em diversas análises, inclusive por Simone de Beauvoir em $O$ Segundo Sexo. Causas: O feminismo marxista entende que a causa da subordinação feminina está na organização da economia e no mundo do trabalho. Objetivos: A libertação das mulheres se daria ao nível das estruturas sociais, com a abolição da propriedade privada e com a transformação da divisão sexual do trabalho. Ícones: Alexandra Kollontai.

Observações analíticas do autor: 1. Essa vertente também tem sido chamada de feminismo material ou dialético. 2. Os enfoques geralmente têm recaído sobre os tradicionais papéis de gênero, sobre o papel feminino na esfera doméstica como reprodutora da família e da força de trabalho para o capital; sobre a questão do trabalho doméstico; a regulação dos direitos de empregadas domésticas; $e$ a desigualdade de classe entre mulheres (patroas e empregadas). 


\section{Considerações finais}

Neste trabalho foi feito um mapeamento do que foi chamado de campo discursivo de ação do movimento feminista na internet através dos diversos desdobramentos desde a década de 90 e sua interface com o boom da internet a partir dos anos 2000, assumindo contornos específicos no Brasil a partir de 2011. Embora estejam amplamente articuladas a processos globais mais amplos e a particularidades inerentes ao campo político e social do Brasil, é evidente que parte da dinâmica desses "feminismos em movimento" não se furta a sua própria historicidade, que por sua vez está agregada a uma narratividade hegemônica que congrega aspectos inseparáveis, como a periodização e a segmentação demarcada por vertentes. Embora não seja nenhuma novidade no pensamento feminista, os resultados obtidos nesta pesquisa sugerem que essa demarcação parece agora reemergir como um aspecto fundamental dessa nova epistemologia do conhecimento, um importante significante político a circular no jogo das identidades feministas nesse campo. Da mesma forma, embora o caráter relacional e binário dessas vertentes também sempre estivesse prescrito na historicidade e na dinâmica de ação do "projeto feminista", a diferença agora é que esse processo se apresenta de forma mais potente, como a gramática por excelência do feminismo cibernético em suas "brigas de vertentes", conluios e alianças. Por outro lado, tais embates se mostram um processo enriquecedor e efervescente, resultando na rápida disseminação do conhecimento, na atualização contínua de materiais já existentes (o despertar de novos interesses sobre produções feministas clássicas, dadas como "ultrapassadas"), e na produção de novos debates e reflexões.

Assim, essa nova epistemologia feminista tecida no bojo da articulação entre o conhecimento feminista formal e as práticas, vivências e experiências cotidianas, quando compartilhadas no ciberespaço, se traduzem como uma experiência social de caráter estrutural e coletivo (Scott, 1999). Isso certamente demanda novas abordagens e agendas em termos teóricos e metodológicos. Em 
primeiro lugar, abordagens capazes de dar conta da dissolução de antigas formas temporais (que obedeciam a um sincronismo entre passado, presente e futuro), que agora cedem seu lugar a uma temporalidade que não só harmoniza passado, presente e futuro, como também se traduz nos termos das novas demandas atualizando seus significados. Segundo, abordagens que compreendam que o caráter multissituado desse processo (Marcus, 1995) requer a identificação e o mapeamento de múltiplas conexões fractais em detrimento das abordagens sistêmicas; uma nova epistemologia em que sejamos capazes de seguir $e$ apreender dinâmicas e conflitos ao invés de atores e grupos sociais. $^{32}$

\section{Referências bibliográficas}

AlvareZ, Sonia. Para Além da sociedade civil: reflexões sobre o campo feminista. cadernos pagu (43), Campinas, SP, Núcleo de Estudos de Gênero-Pagu/Unicamp, jan./jun. 2014 [http://www.scielo.br/pdf/cpa/n43/0104-8333-cpa-43-0013.pdf acesso em: 07 ago 2019].

BoIX, Monteserrat; Miguel, Ana de. Os Gêneros Da Rede: Os Ciberfeminismos. In: NATHANSON, Graciela (org.). Internet em código feminino: teorias e práticas. Buenos Aires, La Crujía Ediciones, 2013, pp.15-38.

Collins, Patricia H. Black Feminist Thought: Knowledge, Consciousness and The Politics of Empowerment. Nova Iorque, Routledge, 2000.

CRENSHAW, Kimberlé. Documento para o Encontro de especialistas em aspectos da discriminação racial relativos ao gênero, University of California, Los Angeles, 2002. Revista Estudos Feministas, vol.10, n.1, Florianópolis, jan. 2002

\footnotetext{
${ }^{32}$ As abordagens sistêmicas subentendem que cada nível é hierárquica e funcionalmente encaixado em outro, ou na qual os níveis superiores controlam $e$ determinam o que sucede nos níveis inferiores, para dar conta da maneira sui generis com que fatores contingentes se combinam com fatores estruturantes (Little, 2006).
} 
[http://www.scielo.br/pdf/ref/v10n1/11636.pdf - acesso em: 07 ago 2019\}.

FACHINI, Regina; FRANÇA, Isadora L. Apresentação Dossiê Feminismos Jovens. cadernos pagu (36), Campinas, SP, Núcleo de Estudos de Gênero-Pagu/Unicamp, jan./jun. 2011 [http://www.scielo.br/pdf/cpa/n36/n36a2.pdf - 07 ago 2019].

FerReIRA, Carolina B. de. C. Feminismos Web: linhas de ação e maneiras de atuação no debate feminista contemporâneo. cadernos pagu (44), Campinas, Núcleo de Estudos de Gênero-Pagu/Unicamp, jan./jun. 2015 [http://www.scielo.br/pdf/cpa/n44/pt 0104-8333-cpa44-00199.pdf - 07 ago 2019\}.

GARBIN, Elisabete M. Cultur@S juvenis, identid@des e internet: questões atuais. Revista Brasileira de Educação, n. 23, Rio de Janeiro, Ago 2013 [http://www.scielo.br/pdf/rbedu/n23/n23a08.pdf - 07 ago 2019].

GONÇALVES, Eliane; PINTO, Joana P. Reflexões e problemas da "transmissão" intergeracional no feminismo brasileiro. cadernos pagu (36), Campinas, SP, Núcleo de Estudos de Gênero-Pagu/Unicamp, jan./jun., 2011 [http://www.scielo.br/pdf/cpa/n36/n36a3.pdf - 07 ago 2019].

HAMmINGS, Claire. Contando estórias feministas. Revista Estudos Feministas, vol. 17, n. 1, Florianópolis, 2009 [https://periodicos.ufsc.br/index.php/ref/article/view/S0104-

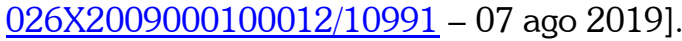

HIRATA, Helena. Gênero, classe e raça: interseccionalidade e consubstancialidade das relações sociais. Tempo Social, vol.26, n. 1, São Paulo, jan./jun., 2014, pp.61-73.

JofFÉ, George. A Primavera Árabe no norte de África: origens e perspectivas de futuro. Relações Internacionais, n. 30, Lisboa, jun.2011, pp.85-116.

LEMOS, Marina G. Ciberfeminismo: novos discursos do feminino em redes eletrônicas. Dissertação (Mestrado em Comunicação e Semiótica), Pontifícia Universidade Católica, São Paulo, 2009.

LÉVI-STRAuSs, Claude. Mitológicas I. O cru e o cozido. São Paulo, Cosac \& Naify, 2006. 
LiMA, Nataly Q.; SANTOS, Maria Salett T. dos. Redes sociais e juventude rural: apropriações de propostas de comunicação para o desenvolvimento em redes globalizadas. Intercom, Revista Brasileira de Ciência da Comunicação, vol.35, n. 2, São Paulo, jul./dez. 2012, pp.225-246.

LiTTLE, Paul E. Ecologia política como etnografia: um guia teórico e metodológico. Horizontes Antropológicos, vol. 12, n. 25, Porto Alegre, jan./jun. 2006, pp.85-103.

MARCUS, George. Ethnography in/of The World System: The Emergence of Multi-Sited Ethnography. Annual Review Of Anthropology, vol.24, California, 1995, pp.95-117.

NATHANSON, Graciela. O que tem a ver as tecnologias digitais com gênero? In: NATHANSON, Graciela (org.). Internet em código feminino: teorias e práticas. Buenos Aires, La Crujía Ediciones, 2013, pp.15-38.

NiCHOLSON, Linda. Interpretando o gênero. Revista Estudos Feministas, vol. 8, n.2, Florianópolis, 2000, pp.9-43.

Piscitelli, Adriana. Recriando a (Categoria) Mulher?" In: AlgRANTI, L. (org.). A prática feminista e o conceito de gênero. Textos Didáticos, n. 48, Campinas, IFCH/Unicamp, 2002, pp.7-42.

Plant, Sadie. A Mulher Digital. O feminismo e as novas tecnologias. Rio de Janeiro, Rosa dos Tempos, 1999.

RIFIOTIS, Theofilus. Desafios contemporâneos para a antropologia no ciberespaço. Revista Civitas vol. 12, n. 03, Porto Alegre, 2012, pp.566-578.

SCOTT, Joan W. Experiência. In: LEITE DA SILVA, Alcione et alii (org.). Falas de Gênero. Santa Catarina, Ed. Mulheres, 1999 [http://historiacultural.mpbnet.com.br/feminismo/Joan_ScootExperiencia.pdf - acesso em: 07 ago 2019].

SORJ, Bila; GOMES, Carla. Corpo, geração e identidade: A Marcha das Vadias no Brasil. Soc. Estado, vol.29, n. 2, Brasília, maio/aug. 2014.

STRATHERN, Marilyn. O gênero da dádiva. problemas com as mulheres e problemas com a sociedade na Melanésia. Campinas, Editora Unicamp, 2006. 
cadernos pagu (56), 2019:e195612 Feminismos em movimento no ciberespaço

VermelHO, Sonia C.et alii. Refletindo sobre as redes sociais digitais. Educação e Sociedade, vol.35, n.126, Campinas, 2014 [http://www.scielo.br/pdf/es/v35n126/11.pdf - 07 ago 2019].

ZANETTI, Julia. Jovens feministas do Rio de Janeiro: trajetórias, pautas e relações intergeracionais. cadernos pagu (36), Campinas, SP, Núcleo de Estudos de Gênero-Pagu/Unicamp, jan./jun. 2011 [http://www.scielo.br/pdf/cpa/n36/n36a4.pdf - 07 ago 2019]. 